\title{
¿LEONES O RATONES?: LOS POSIBLES RELATOS ALTERNATIVOS EN APIAO, CHILOÉ ENTRE BROMAS Y MENTIRAS
}

\author{
LIONS OR MICE? POSSIBLE ALTERNATIVE STORIES IN APIAO, CHILOÉ, \\ BETWEEN JOKES AND LIES
}

Giovanna Bacchiddu ${ }^{1}$ y Daniela Tapia Segovia ${ }^{1}$

\begin{abstract}
Este trabajo explora el lugar que cobra el humor en la vida cotidiana de los habitantes de Apiao, una isla ubicada en el archipiélago de Chiloé. Aquí, lo que subyace a la elaboración de bromas es la práctica de mezclar deliberadamente hechos reales y ficticios, presentados como exageraciones o fantasías, transformando 'ratones en leones', según un dicho local que resume expresivamente tal práctica. Esta amalgama, completamente integrada en la comunicación cotidiana, busca mostrar confianza y familiaridad entre sus protagonistas; pero también tiene manifestaciones negativas, en la difusión de chismes y rumores anónimos sobre otros habitantes. Mediante observaciones recopiladas a través de un trabajo etnográfico, sostenemos que tanto las bromas como los chismes son dos potencialidades de una misma práctica de comunicación local: el mezclar intencionadamente verdades y mentiras.
\end{abstract}

Palabras claves: humor, Chiloé, convivialidad, rumor, mentiras.

This work explores the place of humor and jokes in the daily life of the inhabitants of Apiao, an island located in the Chiloé Archipelago. Here, underlying the making of jokes is the practice of deliberately mixing real and fictitious facts, presented as exaggerations or fantasies, transforming 'mice into lions,' as a local expression graphically describes such practice. This combination, completely integrated into daily communication, aims at showing confidence and familiarity among its interactants. However, it also has negative consequences in the spreading of gossip and anonymous rumors about other inhabitants. Through the analysis of ethnographic data, we maintain that both jokes and gossip are two potentialities of the same practice of local communication: intentional mixing of truth and lies.

Key words: Humor, Chiloé, conviviality, rumor, lies.

El reír en conjunto parece ser un acto universalmente extendido. Aun cuando su forma y contenido puedan tener múltiples variaciones dependiendo de los contextos y los lugares en donde éstas se produzcan, la risa pareciera ser una reacción valorada positivamente en todos ellos. En consecuencia, resulta antropológicamente sugestivo pensar en las múltiples posibilidades de aquello que se pueda considerar gracioso y cuál es el contenido y contexto en donde este fenómeno se sitúa. La risa, y la intención de generarla en los otros, es un fenómeno de importante significancia social que no debiera desatenderse.

Llama la atención entonces, que durante mucho tiempo la antropología no haya prestado mayor interés a la importancia de la socialidad lúdica que forma parte integral de la convivialidad, entendiendo esta como la serie de principios y prácticas cotidianas que contribuyen a la construcción de un sentido de colectividad, mediante compartir diariamente espacios, actividades y conversaciones (Overing y Passes 2000). Esto también resulta curioso considerando que, incluso en el devenir de cualquier trabajo de campo antropológico, una de las múltiples formas en que nos sentimos aceptados por nuestros anfitriones es aprendiendo a bromear como ellos y ellos, produciendo un chiste o siendo objeto de él (Kuipers 2016). No ha sido hasta la literatura etnográfica reciente sobre pueblos amerindios que se ha entregado mucha atención a lo cotidiano (Brandel 2016; Overing

1 Escuela de Antropología, Pontificia Universidad Católica de Chile, Santiago, Chile. gbacchiddu@uc.cl; dltapia@uc.cl 
y Passes 2000; Rivera 2019; entre otros), interés desde el que se han analizado las diversas facetas en el despliegue de la comunicación y los valores expresados. Entre estos aspectos, el humor es parte importante de la armonía que regula y enriquece las relaciones sociales, siendo uno de los rasgos más evidenciables de su comunicación cotidiana.

Por otra parte, trabajos como los de Maximiliano Salinas $(1996,1998,2010)$ han destacado la importancia que tiene la jocosidad, el cultivo y fomento del humor tanto de forma verbal como en otro tipo de manifestaciones dentro de la sociedad chilena. Este también es el caso de la Isla Apiao, una pequeña localidad rural del archipiélago de Chiloé, en donde el humor juega un papel fundamental en la forma en que sus habitantes se comunican en contextos de cercanía y familiaridad. Las bromas, la creación de apodos y la sugerencia de dobles sentidos son formas habituales de expresar cercanía y complicidad con otros. Todas estas manifestaciones humorísticas suelen ocurrir de manera completamente espontánea, improvisadas en medio de conversaciones coloquiales, reuniones familiares o incluso celebraciones rituales $\mathrm{y} / \mathrm{o}$ formales por alguien que usualmente es celebrado por su gran creatividad y picardía. Cuando estas bromas son particularmente exitosas suelen ser recordadas y recreadas por mucho tiempo, pasando a ser un importante rasgo distintivo de quien las haya creado.

¿Que papel tiene este tipo de humor en la vida de esta pequeña comunidad? Lo que hace tan particular este estilo humorístico es el hecho de que, en la práctica, todas estas bromas -referidas como tallas por los locales- se construyen en torno a sutiles alteraciones de la realidad, con el objetivo específico de generar risas. De esta manera la separación entre una broma sutil y una mentira es bastante débil, algo fácil de notar mediante el registro de otro fenómeno social: la difusión de chismes sobre otros isleños o personas relacionadas a la isla. Si bien una historia rápidamente puede sufrir una alteración de su información inicial con el afán de hacer reír a los demás, también puede hacerlo para perjudicar a otra persona. ¿Dónde termina una broma y empieza una mentira? Podemos afirmar que ambas tienen origen en una verdad que es derechamente hiperbolizada o alterada, pero con dos objetivos diferentes: generar risas o bien hablar sobre otro a sus espaldas.

Este artículo se propone abordar el lugar que cobra el humor en una pequeña localidad rural del sur de Chile mediante la importancia que le asignan sus habitantes, la forma que tiene de expresarse y manifestarse en su cotidianidad, y sus potencialidades positivas y negativas mediante la atención a uno de sus principales componentes: la alteración de la realidad factual, o directamente la invención de hechos nunca ocurridos.

Primero, buscaremos introducir el lugar que ha cobrado el humor en las discusiones antropológicas, particularmente sobre pueblos amerindios. Posteriormente, mediante la información levantada a través de un trabajo de campo, se realizará una breve descripción de la Isla de Apiao y las características generales de las relaciones cotidianas entre sus habitantes, y se detallarán las formas en que las bromas suelen manifestarse en diversas instancias de cotidianidades locales. Finalmente, se describe la vinculación del humor con el chisme y su constitución como dos potencialidades opuestas del mismo fenómeno: la mentira y su naturalización dentro de las relaciones locales ${ }^{1}$.

\section{Reflexiones sobre el Humor desde la Antropología}

Desde las ciencias sociales, el humor parece haber cobrado un lugar de interés desde reflexiones tempranas como la de Alfred Schultz (1945), que lo sitúa fuera del marco de la realidad predominante -así como la religión o la magia- y lo considera una "parcela finita de significado" (Schultz 1945:549), en la que se puede entrar o salir voluntariamente o involuntariamente en el transcurso de la vida. Siguiendo esa línea, Peter Berger (1999) habla del humor como un espacio redentor, salvífico en tanto aleja a los sujetos de las complejidades cotidianas; y lo cómico es, por ello, una intrusión al orden habitual en el que es construida la realidad, así como lo sagrado. Sin embargo, es importante tener presente que el hecho de que lo humorístico sea visto como un espacio relativo a lo extraordinario, no implica suponer que no tenga ningún vínculo con la vida cotidiana, en donde su relación con el poder y la agencia constituyen una entre múltiples posibilidades de establecer relaciones creativas con los otros (Veira 2018).

Pese al llamativo papel que pudiese tener para explorar las relaciones sociales, el humor parece haber sido un objeto de interés para pocos antropólogos a lo largo del tiempo (Driessen 2015); sin embargo, una atenta revisión nos muestra que en varios contextos las bromas aparecen como una 
expresión significativa dentro de un conjunto de prácticas culturales que movilizan las relaciones. Una de las primeras aproximaciones remite al trabajo de Radcliffe-Brown (1940) y su reflexión sobre el humor centrada en su potencial funcionalidad. Para el autor, una "relación burlona" [joking relationship] se traza entre dos personas en las que, mediante la permisión de la costumbre, uno de los participantes se ríe del otro, de quien es requerido no sentirse ofendido; de esta manera, esta peculiar relación se encuentra en un límite potencial entre la amistad y el antagonismo, que se puede emplear para conseguir objetivos particulares. Desde su trabajo en África, el autor señala que una "relación burlona" suele darse entre familiares políticos, como forma de cristalizar una alianza entre clanes o tribus, plasmando una forma de organización "de un sistema definido y estable de conducta social en el que [...] se mantienen y combinan elementos conjuntivos y disyuntivos" (Radcliffe-Brown 1940:95).

Alejándose de una perspectiva funcionalista, Mary Douglas (1966:92) propone el entendimiento de las bromas como una posible forma de "anti-rito", operando de manera subyacente como un ataque al sistema de control social. Este ataque no debe ser entendido como un intento de derrocamiento al mismo, sino como una forma de asimilar y vincularse con el peligro o lo considerado peligroso (Berger 1999). Sin intentar subvertir el orden, lo que subyace a lo cómico en realidad es un "juego con la forma", una relativización momentánea del orden que facilita la sublimación de temas prohibidos, haciendo momentáneamente difusas a las jerarquías y límites, dejando temporalmente a la estructura social en suspenso.

Estas observaciones son ejemplificadas con casos de África y el sur de Asia, contextos que luego serían ampliamente explorados por otros antropólogos. Siguiendo la línea propuesta por Radcliffe-Brown (1940), Robert Parkin (1993) se ocupa de analizar el lugar que las "relaciones burlonas" juegan en las distinciones y clasificaciones de parentesco Juang en la India noroccidental, como una forma en la que ritual y coloquialmente se distinguen y reafirman consanguíneos pertenecientes al mismo linaje y afines reales o potenciales, mediante la evasión de la broma. Más recientemente, en una línea similar, Rachel Jones (2007) explora la existencia de "relaciones burlonas" entre los Bamako de Mali como una de las varias estrategias para promover la cohesión social y preservar las identidades locales dentro de la creciente urbanización de su territorio. Asimismo, Youssouf Diallo (2006) ilustra como en el sector occidental de Burkina Faso las bromas entre vecinos y miembros de un misma comunidad étnica se vuelven uno de los marcadores de cohesión e identidad grupal ante la presencia de un entorno intercultural creciente. Otros autores, como Betz y Van Meijil (2016) también señalan dinámicas similares para escenarios como el de los movimientos migratorios de los Tonga a través de Australia y Nueva Zelanda, y como el compartir y transmitir bromas, modismos y chistes de las generaciones mayores a los más jóvenes es visto como una posibilidad de mantener con vida sus tradiciones, su moral y su vida en comunidad.

Por otro lado, para el contexto sudamericano, uno de los primeros en abordar el lugar del humor en la vida cotidiana fue Claude Lévi-Strauss (1969) en el primer volumen de las Mitológicas, describiendo como ciertos mitos contienen elementos irrisorios en su tratamiento. Su interés, sin embargo, radica en la perspectiva de quiénes se ríen y, a diferencia de lo descrito por Radcliffe-Brown (1940), en donde la estructura obliga al receptor a aceptar una broma de forma pasiva, aquí se plantea la posibilidad de reaccionar de forma vengativa. La risa representa un riesgo con el potencial de tener consecuencias fatales, ante lo que se deberían imponer diversas formas de control. Otro que explora las relaciones entre la risa y el poder es Pierre Clastres (1977) entre los Chalupi del Chaco Paraguayo, argumentando que estos se ríen cotidianamente de chamanes o jaguares considerados potencialmente peligrosos; de esta manera, la risa también va asociada a su propia vulnerabilidad y temor.

Las bromas y su relación con el poder son un tema recurrente en el trabajo con comunidades indígenas sudamericanas. Marco Tobón (2016) explora una perspectiva similar a la de Clastres entre los Muina de la zona del Río Caquetá, en la Amazonía Colombiana. En este caso, las dificultades generadas por la ocupación militar del sector por parte de soldados y guerrilleros son contrarrestadas por un repertorio de bromas livianas que los Muina utilizan cotidianamente para relacionarse con ambos grupos, con el objetivo de alivianar la tensión del conflicto o distender situaciones particularmente problemáticas, identificadas como "calientes y amargas" por parte de los locales, para convertirlas en "dulces y frías" mediante el uso estratégico del humor, y vinculando dichos conceptos en una relación metafórica a las prácticas de tratamiento del tabaco y la coca, orientadas a "endulzar y enfriar" lo caliente y convulso. 
La relación entre el humor y el poder esbozada por Clastres también aplica a la vinculación con lo sagrado. Un ejemplo de esto puede encontrarse en el trabajo de Elsje Lagrou (2006) entre los Cashinahua, en el cual se describe como el uso del humor revela valores cruciales de la socialidad y convivencia, en un mundo habitado por distintas entidades que necesitan ser mutuamente seducidas para la construcción de relaciones de colaboración. Las bromas y pantomimas, mediante un uso creativo del lenguaje, subvierten el orden mítico para generar lazos con entidades potencialmente depredadoras. Nuevamente, queda en evidencia la profunda imbricación que tiene el humor con la potencialidad de estabilizar y controlar el surgimiento del peligro, siendo una forma de asimilar y vincularse de manera segura con otro.

El componente humorístico en la vida de estas comunidades, sin embargo, no es vislumbrado únicamente en la relación con otras entidades. Uno de los trabajos fundamentales en destacar su papel en la cotidianidad de una comunidad amazónica fue el de Joanna Overing (2000), donde escribe sobre el rol que juegan las bromas entre pares como una forma de expresar confianza y familiaridad entre los Piaroa. Asimismo, el contenido humorístico de corte ritual en el relato de mitos es clave para presentar, desde un giro jocoso, lo que ocurre cuando los valores fundamentales que rigen el bienestar y la convivencia colectiva son transgredidos y reemplazados por la codicia, la soberbia o todo lo que oblitera el mantenimiento de estas relaciones de confianza y cercanía necesarias para sostener exitosamente a una comunidad. Los mitos son encargados de crear una "buena risa", producida cuando los miembros de la comunidad pueden reír juntos y no los unos de los otros. Así, el humor se constituye como una fuerza con potencial autónomo, vinculado a una suerte de hechicería, pues actúa sobre los sentidos de los sujetos.

En cierta continuidad con lo anterior se encuentra, finalmente, el trabajo de Dan Rosengren (2010) entre los Matsikenga del Amazonas peruano. En este caso, se sostienen observaciones similares a las hechas por Lévi-Strauss, respecto a la importancia y el cuidado puesto al acto de bromear sobre algo o alguien. Para los Matsikenga, pese a que la búsqueda de una "buena risa" aparece también como un reflejo de una convivencia armoniosa, esta nunca pareciera hacerse a costa de otros miembros de la comunidad. El reírse de otro también puede entenderse como la potencial incitación a un conflicto y un evento que perturba las relaciones pacíficas, por lo que el contenido humorístico pareciera nutrirse, primero, de situaciones absurdas (más que burlarse de personas en específico) y en personajes relativamente lejanos: individuos fallecidos o personajes históricos.

Es en este sentido en que se da cuenta de como el humor, al igual que en casos detallados con anterioridad, parece ser entendido como un poder que se desplaza siempre en medio de una frontera abierta a dos posibilidades: una positiva, en la generación y fortalecimiento de los lazos comunitarios, y una negativa, que remite al potencial de dañar e incitar la venganza de la víctima. Tal como revisaremos en las líneas siguientes, este carácter potencialmente abierto es otra de las características centrales del humor en Apiao y se debe, sobre todo, a la peculiaridad del componente que mezcla deliberadamente realidad y ficción.

\section{Esta Investigación: La Isla de Apiao, Chiloé (Chile)}

Este estudio se enmarca en una investigación basada en un trabajo de campo etnográfico de largo plazo en la Isla Apiao, ubicada en el nordeste del archipiélago de Chiloé. La conducción del mismo ha sido realizada de forma continuada entre los años 2001 y 2003, seguido por visitas frecuentes hasta la actualidad. Junto con residir en la comunidad, se participó activamente de sus actividades y experiencias cotidianas y de las relaciones entre sus habitantes con el objetivo de conocer las formas de vida locales, principalmente lo respectivo a las manifestaciones de religiosidad y la construcción de relaciones de parentesco, así como los detalles minuciosos de las formas de relacionarse entre individuos y familias ${ }^{2}$.

Apiao es una pequeña isla de 13 kilómetros cuadrados, perteneciente a la comuna de Quinchao en Chiloé (Chile), y que hasta el 2017 era habitada por aproximadamente 9.000 habitantes, de los cuales 6.600 residen en zonas rurales. De estos, aproximadamente 700 residen en Apiao (CENSO 2017) ${ }^{3}$. La mayoría son descendientes de Huilliches, una rama meridional del pueblo Mapuche, y aún conservan sus apellidos indígenas intercalándolos con algunos nombres y apellidos españoles. Este lugar, como el resto de las islas chilotas, fue convertido al cristianismo por los misioneros jesuitas durante el siglo XVII (Barrientos 2012 [1932]), y la ocupación formal y definitiva de familias colonas se consolidó en la segunda mitad del siglo XVIII con el advenimiento franciscano en la isla (Cárdenas et al. 1991; Urbina 1983). 
Tal como es observado en gran parte del área del archipiélago, esta sociedad se caracteriza por ser fuertemente igualitaria, como es explícitamente indicado en múltiples ocasiones por sus habitantes, que reiteran ser "todos iguales" o "todos parejos", y rechazan cualquier posición que implique autoridad o poder entre los habitantes de la misma isla. Las raíces e implicancias de este pensamiento igualitario son tan profundas que tareas como la elección de un representante, como es el caso de los fiscales o el presidente de la Junta de Vecinos, pueden volverse sumamente dificultosas, pues implícitamente involucran la declaración de una posición de superioridad o diferencia con el resto de la comunidad, aun tratándose de cargos voluntarios y que impliquen prestar un servicio a todo el grupo. Asimismo, las relaciones con forasteros pueden ser complicadas, muchas veces caracterizadas por la hostilidad, pues se entiende que si alguien no es de la isla por definición ha de ser diferente. Estas declaraciones de igualdad apuntan a considerar a la comunidad relativamente uniforme y homogénea, lo que es sostenido y defendido con esfuerzo, pues protege a las relaciones de eventuales conflictos (para una descripción más detallada, véase Bacchiddu 2012b, 2017, 2019).

El establecimiento de todas las relaciones sociales en Apiao ocurre en el espacio doméstico, donde la gente vive, trabaja y atiende a las visitas (Bacchiddu 2019). Los hogares consisten en una o más construcciones rodeadas de terrenos separados por cercas, que funcionan como viviendas pero también como unidades productivas independientes. La vida en Apiao está organizada alrededor de su entorno natural y está estrictamente ligada a él. Los residentes dividen su tiempo y ocupaciones cambiando frecuentemente en su trabajo respecto a dos polos: la tierra y el mar. Esta forma de organizar la vida en torno a la producción doméstica ha dado origen a construcciones asociadas a los roles de género y a la división de las tareas dentro del hogar y el cuidado de los hijos. Sin embargo, estas no son fijas, y también han sido actualizadas y reconfiguradas a partir de los mismos cambios experimentados en las labores productivas de la isla, como la aparición de empleos asalariados en minería y en la industria salmonera (para una discusión detallada, véase Saldívar et al. 2018).

La gente organiza su vida en torno a la tierra, en la que cultivan el campo y sus animales. El mar es el principal punto de referencia en el paisaje, siendo también un recurso que suministra productos comestibles: mariscos, peces y algas, junto a otros productos que son procesados y vendidos. La playa es el lugar de llegada para las lanchas y el punto de partida para quien viaja, y donde usualmente los peregrinos que asisten a festivales religiosos se reúnen, esperando que llegue la estatua milagrosa de San Antonio para ofrecerle una bienvenida (Bacchiddu 2011).

Otro aspecto relevante de las relaciones en la isla es que aún en la esfera cotidiana éstas se hallan dotadas de un alto nivel de formalidad y ritualidad, como un código tácito de reglas y modales que siempre tenderán a regir en cualquier contexto ajeno al ámbito familiar y doméstico. Por ejemplo, en el camino las personas suelen saludarse con un gesto formal, extendiendo los brazos para darse las manos; asimismo, cada vez que se va a pedir algo siempre se hace ritualmente ${ }^{4}$, con maneras determinadas. $\mathrm{La}$ socialidad se articula a través de actos formales de hospitalidad más que en encuentros casuales; si dos personas se encuentran por casualidad en la isla o en una lancha que los traslada hacia otro lugar, lo común es saludarse sin mayor interés o incluso ignorarse por completo. Por el contrario, si las personas se visitan se pone en práctica un elaborado código de decoro acompañado por una sucesión de actos rituales que involucran la ofrenda y recepción de distintos alimentos y bebidas alcohólicas, adornados de un discurso lleno de formas establecidas.

En contraste a estas prácticas, en apariencia rígidas, las personas que comparten vínculos estrechos como parientes, vecinos cercanos o amigos suelen compartir en instancias en donde las bromas o tallas son bastante comunes. En Apiao, la risa constituye una importante dimensión de convivencia íntima y cercana. Al igual que el humor, la memoria también es un elemento importante en la gestación de un sentido comunitario ${ }^{5}$ : continuamente se recrean acontecimientos, recuerdos y vínculos con personas lejanas o incluso, mediante los sentimientos sublimados en lo que hemos definido "memoria activa", se activan o anulan relaciones de parentesco (Bacchiddu 2012a). De esta misma manera, el recordar y reír con las bromas hechas en el pasado cobra una parte importante de la forma de relacionarse en la isla.

\section{Las Tallas: Construcción Cotidiana de una Rutina Cómica}

En Apiao las bromas son coloquialmente conocidas como tallas. Una talla hace referencia a un amplio 
espectro de posibilidades humorísticas que van desde la emisión de comentarios de carácter cómico hasta la gesticulación, la imitación de movimientos o los gestos de otros, la invención de apodos y múltiples formas de expresión imaginables. Junto a esto, se caracterizan por ser generalmente espontáneas, surgiendo de manera improvisada por uno de los presentes y en la medida que se gesten las condiciones que las permitan (un comentario sobre algún acontecimiento, mencionar a alguna persona, etc.). Lejos de ser un elemento preparado, el potencial humorístico de la talla recae en su carácter inesperado y en la perspicacia de su autor para aprovechar un momento propicio y generar risas entre los presentes.

Las tallas tampoco parecen tener un público ni un escenario determinado, pudiendo surgir en múltiples situaciones y aludir a cualquier persona según la ocasión lo amerite. La intención de provocar y hacer reír a los presentes pareciera enmarcarse en circunstancias extremadamente flexibles, pues solo depende de la disposición de un potencial autor para jugar creativamente con las circunstancias. A continuación, se describirán tres situaciones o escenarios en donde el surgimiento de tallas o provocaciones de carácter cómico son comunes entre los integrantes de la comunidad, cada una de ellas ilustrada por una viñeta enmarcada en el trabajo de campo.

\section{(a) Tallas en espacios formales}

Si una persona se siente a gusto hace de todo para entretener a los demás, lo que puede darse incluso en instancias extremadamente formales, donde actitudes de corte humorístico parecieran ser intuitivamente excluyentes. Un ejemplo claro es el caso de las novenas religiosas, encuentros de oración en donde hombres y mujeres se reúnen durante nueve días en ofrenda a un santo por un favor concedido (Bacchiddu 2012b). Las novenas son instancias de carácter ritual extremadamente importantes, planificadas con meses de anticipación y en donde la comunidad participa activamente en miras de apoyar al deudo que la organiza, siendo la principal manifestación religiosa de la zona, por lo que inicialmente es fácil pensar que ningún elemento de corte jocoso estaría socialmente permitido.

Sin embargo, la flexibilidad de posibilidades antes descrita queda claramente demostrada con la gran cantidad de tallas recordadas en estas instancias. Una de ellas es protagonizada por Pedro, un joven sordomudo que sacó carcajadas en medio de una novena, justo en el intervalo entre un rosario y otro. En este contexto, hombres y mujeres asisten sentados en bancas opuestas, los unos frente a los otros, y Pedro se encontraba en el sector masculino justo al lado de un vecino. Sabiendo que tenía a todas las asistentes mirando desde la banca de enfrente, comenzó a imitar mediante gestos a su acompañante, aludiendo que éste gustaba de los excesos al imitar con sus manos el gesto de beber alcohol de una botella y el vaivén propio de una persona ebria. Tan pronto como la víctima se volvía hacia él, cambiaba inmediatamente de semblante pareciendo serio y concentrado en las plegarias, para volver a sus imitaciones cuando su vecino dejaba de prestar atención. La secuencia era bastante divertida, y su gracia se acentuaba aún más al situarse en un contexto solemne. Era claro que Pedro estaba perfectamente consciente de esto y que aprovechó la situación y sus matices con gran destreza para captar la atención y hacer reír a todos los asistentes, quienes recordaron la situación por mucho tiempo después.

En esa misma línea se puede encontrar un paralelo entre hacer tallas y bailar. La cueca, el baile nacional chileno, tiene mucha popularidad en Chiloé, en donde incluso se encuentra una variante propia: la cueca chilota. Además, en Apiao el baile tiene una importante connotación religiosa, también presente durante las novenas. La cueca chilota responde a un ritual de bastante formalidad, donde las parejas que bailan siguen una coreografía fija y sus cuerpos y miradas no entran jamás en contacto. Quienes bailan en instancias religiosas son apreciados por todos, pues sirven al santo y a los fieles. No obstante, la formalidad de un baile puede ser una instancia para generar una talla, pues quien baila tiene la posibilidad de destacar como buen bailarín o como personaje cómico. Si alguien baila de manera graciosa puede desencadenar la atención de la audiencia, siendo recordado como alguien "muy chistoso para bailar" e incluso imitado y parodiado. Aún cuando no sea la intención inicial la talla y el baile, aparentemente opuestos, pueden coincidir en un solo espacio, motivando la aparición de bromas o la identificación de un personaje con una característica o anécdota graciosa sobre el mismo.

\section{(b) Tallas sexuales}

Las mujeres raramente hablan abiertamente de cuestiones relacionadas a su vida sexual, y lo más 
común es que estos temas sean referidos de forma humorística. Las conversaciones explícitas sobre sexualidad no suelen ocurrir en Apiao, ni siquiera en forma de rumores, pero las bromas o alusiones humorísticas sí son bastante recurrentes. Las tallas más comunes de corte sexual son las que evidencian cierto grado de cercanía entre las personas en determinadas situaciones. El objetivo de estas bromas no es en ningún caso el incomodar a los protagonistas, sino provocar risas entre los presentes. Asimismo, cualquiera que es objeto de este tipo de bromas suele recibirlas bien y consentir la exposición a la que es sometido, sustraerse del juego no parece ser una opción admisible.

En una cena familiar ocurrió que uno de los jóvenes preguntó a sus abuelos acerca de cómo se conocieron, y el abuelo comenzó a contar una historia llena de guiños sexuales mientras la abuela intentaba desviar su discurso, pero sin mostrarse explícitamente incómoda o frenar la situación. Entre tanto, vino y una serie de bebidas alcohólicas comenzaban a circular por la mesa, mientras los comensales animaban la historia del abuelo, exclamando que no le permitieran beber a su esposa o "se iba a poner cargante" [sexualmente insistente respecto de su marido]. El comportamiento sexual de la abuela, oculto según la etiqueta y la decencia, fue improvisadamente puesto en evidencia, con el objetivo de provocar risotadas en un contexto de cercanía y confianza.

Otra forma común de bromear respecto a la sexualidad propia o de los demás es mediante la alusión de metáforas popularmente conocidas en la comunidad, siendo la más común la que hace referencia a los mariscos. En general todo el vocabulario asociado a los mariscos, ya sea sus nombres o las acciones vinculadas a su recolección y preparación, están asociadas metafóricamente al sexo y a la actividad sexual. Además, los moluscos, crustáceos y algas son popularmente conocidos por tener altas cantidades de yodo (Huang 2005; Ther 2008; Weber 1905), considerado también un fuerte afrodisíaco, lo que es constantemente citado en un estilo humorístico como una explícita referencia sexual. Por ejemplo, uno de los jóvenes que vende almejas en la isla suele bromear ["echar la talla"] con la gran cantidad de yodo de las mismas, diciéndole a sus clientes que seguramente, para no desperdiciarla, estarían "aprovechándola toda la noche".

Ejemplos como estos muestran un tipo de comunicación diametralmente opuesta a la ritualidad que se despliega cotidianamente durante los encuentros formales entre personas y especialmente durante las visitas, marcadas por formalidades rígidas y un código de decoro entre interlocutores, aunque estos estuvieran emparentados (Bacchiddu 2019). Es importante destacar que ambos registros comunicativos son parte del mundo relacional isleño, aunque en contextos y oportunidades diferentes. Si la ritualidad del atender a las visitas es parte de los deberes diarios, se necesitan contextos conviviales particulares para que las condiciones de confianza y distensión se presenten, ofreciendo la oportunidad de que florezca la creatividad.

Otra inversión importante, y aún más evidente en las tallas sexuales, es que permiten tratar indirectamente temáticas particularmente íntimas y que de otra manera nunca serían formuladas en la isla, exponiendo también a otros sin necesariamente perturbar su intimidad ni violar algún código social específico. Ejemplos como estos han sido registrados en otros trabajos etnográficos como el de Maurice Said (2016) con los sinaleses de Sri Lanka, en donde el compartir bromas sexuales entre hombres que manifiestan un grado importante de cercanía o amistad se convierte en una forma recurrente de mostrar confianza, solidaridad y empatía, así como una posibilidad de poder hablar de su propia intimidad en un contexto socialmente permitido.

\section{(c) Posibles amoríos: Tallas entre marido y mujer}

El crear fantasías sobre historias extraconyugales es también una forma común de bromear, más aún como una forma en que los propios integrantes del matrimonio bromean con su pareja. La broma siempre es hecha buscando presentarla como una antítesis de la realidad, por lo que bromear al respecto no es algo arriesgado; por el contrario, se considera un gesto divertido con inmediato efecto cómico.

Por ejemplo, en una ocasión en casa de una familia conformada por un matrimonio de mediana edad, había llegado la noticia de que Salvador, un vecino, se había quedado inesperadamente a pasar la noche en una isla cercana mientras Lucía, su mujer, se encontraba enfadada por la ausencia de su marido. Ella tenía un pequeño almacén en su casa y justamente esa noche se necesitaban con urgencia baterías. El dueño de casa se ofreció rápidamente para ir al almacén a comprar lo necesitado y su mujer, entre risas, le preguntó si estaba pensando en ir para sustituir a Salvador. Él devolvió rápidamente 
la broma y le contestó: "Si, ahora mismo voy y le digo a la Lucía: ¿Está Salvador?, ¿No? Bueno, ¡yo vine a reemplazarlo!". Todos los presentes rieron gustosamente, y la talla fue repetida varias veces el día siguiente.

En otra ocasión, en medio de la celebración de la faena de un cerdo, don Renato, uno de los asistentes más ancianos, comenzó a contar historias rodeado por los demás comensales. Rápidamente encontró el momento adecuado para empezar a bromear, hablando de "la francesa", una estudiante de antropología que había pasado un tiempo en la isla. La mayoría decía que vivía una vida retirada y que transcurría la mayor parte del tiempo dentro de su casa anfitriona sin visitar ni hablar con nadie, siguiendo una dieta bastante particular ${ }^{6}$. El abuelo insistió varias veces en hablar sobre la mujer, haciendo comentarios con el claro objetivo de causar risas: “ ¿La francesa? ¡Esa más que nada lo pasaba encerrá' con Francisco, echaban a la Nadia pa' afuera, y ellos dos encerra'os!". La burla no era sino una astuta combinación de un hecho real con una mentira: la joven extranjera, en efecto, pasaba mucho tiempo encerrada, agregándose el hecho de que ese tiempo lo pasaba junto a Francisco, el dueño de la casa en donde se quedaba, pero remata con un hecho completamente falso: que "la francesa" y Francisco echaban a Nadia -su esposa- para pasar el tiempo juntos.

Lo cómico de estas situaciones reside precisamente en la perspicacia que se tiene de tomar hechos reales y añadirle pequeños guiños de falsedad, que una vez verbalizados desvanecen cualquier posibilidad de ser ciertos. Si llegasen a existir sospechas reales de una infidelidad ninguno de los presentes osaría bromear al respecto, pues se estaría transgrediendo un tabú. Este tipo de asociaciones permiten verbalizar ciertas mentiras con la certeza de que no se está cometiendo ningún acto ofensivo o peligroso, y así aludir sutilmente a cuestiones de las que cotidianamente no se habla.

\section{La Memoria de Tallas Exitosas}

Una característica central de todas las tallas en Apiao es el ser elementos constitutivos en la identificación y evocación de sus protagonistas, sean estos los autores o las víctimas de las mismas. Si una talla es particularmente perspicaz, creativa y picaresca va a tener mucho éxito entre el público que la haya disfrutado, lo que no solo es apreciable en el preciso instante en que ocurre sino que a lo largo del tiempo. En general, todas las tallas exitosas tienden a permanecer en la memoria colectiva, repitiéndose y recreándose en múltiples ocasiones. Los episodios particularmente exitosos pasan a ser una suerte de "clásicos", citándose repetidas veces y a los que cada miembro suele añadir detalles o reformularlos de distintas formas, mutando a lo largo del tiempo pero permaneciendo constantes en su difusión.

Recordar las bromas es importante pues termina siendo una manera de evocar personas y situaciones. Si una broma se considera divertida será repetida en más de una ocasión, asociándose a su autor y llegando a formar parte de una suerte de "repertorio" personal, donde se incluirán las bromas hechas por la persona y aquellas que la han afectado directamente. Dada la importancia local otorgada al recordar a los otros como una forma de mantener activas las relaciones (Bacchiddu 2010), entender el potencial de las tallas como una forma en la que se materializa dicho cuidado puede dar luces de la frecuencia y la naturalidad con la que estas son enunciadas en la comunicación cotidiana de la isla.

Uno de los casos en que esta faceta de las tallas fue vista con mayor claridad durante el trabajo de campo fue con las bromas que circulaban en torno a una de nosotras y Andrés. En una ocasión este joven decidió invitar a la autora para que lo fuera a visitar "a la casa"; sin embargo, y contrario a lo que prescribe la norma local, en vez de invitarla a su propio hogar la invitó a la casa de los patrones en donde trabajaba. Esta iniciativa suscitó gran regocijo entre los conocidos y amigos de Andrés, pues no tenía derecho a invitar a nadie a la casa de alguien más y su comportamiento fue inapropiado. Fue a partir de ese momento que, cada vez que se mencionaba a la autora y sobre todo a Andrés, siempre había alguien que recordaba la invitación, provocando carcajadas entre todos. A lo largo del tiempo la historia fue adquiriendo nuevos matices, lo que incorporaba material al repertorio de ambos protagonistas. En una ocasión, incluso la autora continuó con la seguidilla de bromas sobre ambos, pues encontrándose de visita en la familia de los patrones del joven y sentándose a su lado para comer, poco después comentó entre los presentes de manera jocosa "allí estuve sentada, al 'laito' de mi Andrés", insinuando de forma indirecta la posibilidad de un coqueteo entre ambos. Los presentes rieron a gusto y posteriormente la frase comenzó a formar una nueva parte de la misma historia, como otro episodio digno de contar y recordar. 
Esta historia da cuenta con claridad, además, del potencial de que en el acto de recordar las tallas estas sean extremadamente flexibles, quitando o incorporando elementos según quien las recuerde y el contexto en donde sean recordadas. Una broma exitosa, si bien es mantenida en su esencia, puede variar enormemente desde su versión inicial al momento de circular entre las distintas voces de la isla. Otro elemento importante que se desprende de dicha flexibilidad y mutabilidad, ilustrado con el comentario hecho por la autora a propósito de la talla inicial, es que el contenido humorístico de las mismas pareciera yacer en una mezcla entre algo real, un evento o hecho que efectivamente ocurrió, y algo posible pero poco probable, una posibilidad cuyo contenido humorístico se desprende de su mismo carácter absurdo.

\section{Lo Esencial de una Talla: Combinando la Verdad y la Mentira}

Tanto las tallas de Pedro sobre la vida de excesos de su vecino, el vendedor de mariscos sobre el buen uso de su yodo, las invenciones de posibles amoríos entre Francisco y "la francesa", o entre la autora y Andrés, tienen como punto en común construirse sobre una suerte de estructura en la que se yergue todo el contenido humorístico en Apiao: la mezcla deliberada entre eventos reales y situaciones ficticias. En ninguno de los casos la elaboración de la talla hacía una referencia literal y exacta a la realidad sobre la que se sustentaba; por el contrario, parecía valerse de la misma para luego decorarla con exageraciones o directamente la adhesión de hechos falsos, en los que precisamente recaía su componente cómico. Estas historias muestran que de un hecho de origen verídico se pueden extraer pequeños detalles incongruentes, lo que tiene el objetivo explícito de generar risas. La creatividad y el éxito de un bromista yace precisamente en esta capacidad de mezclar perspicazmente eventos reales y conocidos por todos con exageraciones, incoherencias o falsedades, dando por resultado historias absurdas y sin sentido, porque desafían el orden de las relaciones sociales establecidas y contrarían los principios aceptados de la organización social diaria. Es por eso que son celebradas y recordadas o, tal como se ha detallado, complementadas por otros con nuevas exageraciones o falsedades, a fin de generar creaciones colectivas.
Pareciera ser que precisamente en la clave de su carácter cómico -el mezclar verdades y mentirastambién se condensa la flexibilidad de una talla para ser colectivamente construida y transformada para añadirle mayor potencial humorístico. Usualmente, cuando uno de los presentes agrega contenido a una talla a través de una nueva exageración u otra mentira, se valida a la misma como broma, negando la veracidad de su contenido. El contenido de una talla es siempre inocuo: el vecino de Pedro nunca había dado indicios de consumir alcohol de manera excesiva, ni ninguno de los romances descritos habían despertado sospechas de ser verdaderos. Una talla nunca pretende instalar un manto de dudas respecto de sus protagonistas; por el contrario, lo que hace es validar el carácter inadmisible de dichas declaraciones.

La presentación de las bromas en forma de mentiras, exageraciones o incongruencias ha sido documentada con detalle en otros contextos etnográficos como en Melanesia (Nachman 1984) o Fiji (Toren 2005). En estos casos se ha destacado la profunda imbricación que tienen ambas acciones al punto de ser aparentemente indistinguibles, lo que incluso puede presentar problemas en el desarrollo del trabajo de campo de un investigador poco habituado al contexto. A diferencia de estos casos, aun cuando una talla pareciera requerir de una mentira para constituirse como tal, la forma de emplear la misma es mediante su exhibición y puesta en evidencia.

La importancia de esto recae en que, negando desde el comienzo la intención de infundir dudas entre los otros, una talla no es sino una mentira completamente inofensiva. Al mostrar poca probabilidad de causar daño en sus víctimas ni despertar en ellas una reacción negativa, el hacer bromas permite hablar o hacer visibles, aunque sea de manera tangencial, distintos temas cuyo abordaje sería incómodo o derechamente inapropiado en otros contextos. Siguiendo a Michael Apter (1989), el presentar una broma como una forma de juego permite expresar mensajes sin comprometer la definición o postura de su emisor, desde una ambigüedad que con ciertos tópicos puede ser cómoda e incluso estratégica. Esto último se hacía evidente, por ejemplo, con las tallas sexuales o las que involucraban inventar posibles amoríos, pues de hecho permitían a sus autores hablar sobre temas como la propia pareja o la situación sentimental de otros -sus víctimas- siendo estos temas imposibles de referir de forma explícita, al ser un acto de indiscreción. Tal 
como veremos, dicha amalgama entre lo real y lo fantasioso se expande constituyéndose como fuerza autónoma, que incluso puede adquirir una expresión opuesta a lo hasta ahora descrito, con consecuencias negativas, remplazando el humor con la malicia.

\section{El Efecto Opuesto de la Ficción: El Chisme como Cadáver Exquisito}

En el mismo trabajo antes descrito en Fiji, Christina Toren (2005:275) se pregunta provocativamente qué ocurriría si la gente con la que está conviviendo no dice necesariamente la verdad, existiendo la posibilidad de que todo su trabajo de campo se sustente en mentiras. Tomando en consideración que el poner atención a los discursos, las opiniones y las prácticas de los interlocutores constituye los cimientos de cualquier etnografía, la posibilidad de que ninguno de estos sea real puede minar la reflexión antropológica en sus bases más profundas. Sin embargo, también existe la posibilidad de que pueda ofrecernos luces sobre otra dimensión reveladora en la vida de algunas sociedades: el papel que juega la mentira en su cotidianeidad.

En Apiao, pese a que el tratamiento de esta amalgama deliberada entre verdades y mentiras es mayoritariamente usado de forma cómica, la modificación de la verdad no siempre produce burlas inocentes. El acto de mentir puede cobrar más de una forma en la isla, y bajo el mismo método sobre el que opera la creación de tallas se puede alterar parcialmente la realidad con objetivos maliciosos. $\mathrm{Si}$ la exageración o la falsificación de eventos es usada fuera de un contexto jocoso o de familiaridad entre los interlocutores, aquello que en otro caso podría ser una talla se transforma simplemente en una mentira sobre alguien, la que adquiere vida, forma y consecuencias propias.

¿Cuál es el lugar que tiene la mentira en Apiao? El entendimiento de la mentira, o la acción de mentir, abarca diferentes niveles y contextos en la isla. Una forma habitual de mentir consiste en asentir ante una petición sin cumplirla, o asentir una pregunta o afirmación sin ser cierto, con el fin de evitar algún tipo de reacción negativa. Por ejemplo, al preguntar alguna información que la persona interpelada no quiere revelar, o pedir un favor que la persona prefiere no hacer, habitualmente ésta contestará con un "iclaro!", sin que necesariamente esta respuesta venga seguida de una conducta o acción consecuente. Esta situación se produce recurrentemente, pues en el contexto local el mentir siempre es preferible a una negación explícita, la que sería consideraba como un acto descortés y que podría dañar profundamente las relaciones con el otro (Bacchiddu 2010); en estos casos efectivamente la mentira es un acto de cordialidad.

Empero, la forma de mentir que más interesa en este contexto responde a la acción de tomar un hecho y modificarlo, distorsionándolo o agregando contenido falso, pero haciéndolo circular como si fuese real. Este tipo de prácticas ya han sido documentadas en otros trabajos en contextos rurales; por ejemplo, Gilmore (1978) ilustra la tendencia al chisme en un pueblo español y a la forma en la que los chismes se construyen colectivamente, definiendo prácticas similares a las de Apiao como "chismear inspiradamente" (inspired gossipmongering). Otro escenario similar es descrito etnográficamente por Paolo Apolito (1990) en un pueblo italiano, donde la población en general es extremadamente devota de la Virgen María, y el hablar y contar historias sobre sus recientes apariciones es algo muy recurrente, aún cuando estas en realidad no den pruebas de haber ocurrido realmente. En efecto, pese a que esta forma de alterar los hechos es común y puede tener múltiples motivaciones, interesa una en particular que comparte directamente con la talla: la búsqueda por exponer y controlar temas y eventos que de otra forma serían inaccesibles.

¿Cómo son y en qué contexto surgen este tipo de mentiras? Las historias que ilustran esta práctica son muchas (Bacchiddu 2011), pero quizás la que mejor las resuma tiene como protagonista a una de nosotras, en las celebraciones de las fiestas patrias. La celebración de estas festividades tiene gran importancia en la isla, y precisamente ese día la comunidad había organizado varias actividades, entre las que se encontraba un torneo de fútbol y una fiesta con música y bebidas. Ya avanzada la noche, algunos asistentes decidimos retirarnos dado el frío y la gran cantidad de gente ebria, por lo que para retornar resolvimos cruzar por el canal en bote. Tomamos un bote que se encontraba en la orilla y, a mitad de camino, nos encontramos con un vecino que ofreció cruzarnos, por lo que saltamos de una embarcación a otra y pasamos largo rato charlando con él. La velada terminó de forma tranquila y agradable, nada hacía pensar que hubiera pasado algo más, hasta transcurridas un par de semanas.

Habiendo olvidado la situación, fuimos a visitar a unos amigos en otro sector de la isla, cuando nos encontramos con una pareja conocida que 
muy preocupada nos preguntó si ya nos habíamos recuperado del accidente. En efecto, alguien les había contado que luego de la fiesta una de nosotras había intentado robar un bote, pero había resbalado y había caído abruptamente al canal, supuestamente ebria, ahogándose y a punto de perder el conocimiento, hasta que sus gritos de auxilio alertaron a los vecinos que se precipitaron a sacarla. La historia parecía extraordinaria, pero la pareja estaba fehacientemente convencida de que los hechos habían ocurrido de esa manera. Como esta versión había sido replicada por varias personas en el transcurso de estas semanas, no tenía ningún sentido rastrear su origen. Una vez llegados al destino, contamos rápidamente lo escuchado, y pese a que todos reaccionaron de forma discreta, la anciana de la casa dijo: "¡Ah, entonces no era verdad!", revelando claramente que la noticia también había llegado hasta ellos.

Historias como esta son abundantes en la isla. Rumores, noticias sobre accidentes y una serie de otras invenciones circulan cotidianamente entre las conversaciones repitiendo, curiosamente, una fórmula que ha sido ampliamente expuesta: la conjunción de un hecho real y la adhesión de exageraciones y falsedades. Estas historias también tienen otro antecedente en común con las tallas: ambas se construyen de manera colectiva, mediante la adhesión de elementos de diferentes autores para construir algo diferente a lo inicial; sin embargo, en este sentido, se deben destacar dos puntos de diferencia importantes. Primero, en el caso de los chismes es notorio que la construcción colectiva cobra muchísima más relevancia que en el caso de las bromas pues aquí, a diferencia de las tallas que son reconocidas y conferidas a su autor, los chismes se presentan como construcciones anónimas, cuyo potencial recae en su capacidad de circular entre la mayor cantidad de personas posibles. Esto es lo que, siguiendo a Zires (2005:46), define su "régimen de verosimilitud" mediante su interdiscursividad, es decir, la yuxtaposición de distintos discursos y voces que impiden poner en duda lo dicho. Efectivamente, una segunda característica que distingue al chisme de la talla es que, en vez de que la exageración o la mentira se presenten como algo incongruente y completamente inverosímil, éstas están tan profundamente compenetradas en el relato que hacen imposible poner en duda la historia.

Podemos decir, por lo tanto, que los chismes en Apiao tienen una forma de construcción similar a la de un "cadáver exquisito" (cadavre exquis); es decir, como el juego surrealista en donde cada participante añade contenido a la obra original desconociendo el contenido exacto que le antecede, y dando como resultado una construcción colectiva con una vida completamente original e independiente a la inicial. Esta manifestación de la mentira termina constituyéndose como una fuerza con agencia propia, sin autoría y sin un objetivo definido, lo que hace prácticamente imposible frenar su circulación, cambio y crecimiento. La agencia de los chismes los hace verosímiles tan solo por el acto de ser difundidos, de esta manera el hablar de determinados hechos los convierte en 'verdaderos', aun cuando puedan no haber ocurrido. Esto último puede ser considerado particularmente problemático al tomar en cuenta que, aun cuando no sea su finalidad explícita, a diferencia de la talla el contenido que circula no es siempre inofensivo, llegando a tener efectos negativos en la víctima y protagonista del chisme, o generando reacciones inesperadas entre sus cercanos.

\section{Conclusiones: ¿Leones o Ratones?}

En El Barbero de Sevilla de Rossini, con la famosa aria "La calunnia è un venticello" (la calumnia es una brisa), se alude sutilmente a la capacidad de estos relatos para viajar velozmente, como el viento, entre distintas voces y con distintas formas. Parece claro que prácticas como bromear o chismear son universales, aun cuando sus formas de manifestación y posibles finalidades puedan ser variopintas. En Apiao las mentiras tienen un amplio rango de manifestaciones y potenciales consecuencias; pese a ello, se encuentran plenamente integradas como elementos cotidianos en las relaciones que los isleños cultivan unos con otros. Siendo una comunidad pequeña, relativamente aislada, sin el control del Estado o la Iglesia, y sin ninguna figura de aparente control, es fácil preguntarse: ¿es posible que algunos isleños intenten controlar o acceder a información de sus coterráneos a través de estos modos?

Esta práctica de mezclar continuamente los real y lo falso entre los isleños es reconocida como algo popular, que forma parte de su propio estilo de comunicación. Al hablar del lugar que cobra la mentira cotidianamente, se mencionó un dicho local que resume en gran parte esta premisa: "Aquí en la isla, de un ratón hacen un león". Ambos animales mencionados en este dicho popular son parte de la experiencia local, vivida o imaginada. Los ratones, 
parte integral de la vida en el campo, son tolerados y manejados como elementos de un conjunto de deberes más o menos fastidiosos, pero no intolerables. Los leones (pumas) ${ }^{7}$-aún estando ausentes en la isla- son frecuentes en Chiloé continental, en la costa cercana donde muchos habitantes de Apiao viajan con regularidad para faenar algas. $\mathrm{Si}$ los ratones son comunes, los leones son verdaderamente excepcionales, y encontrarse con uno puede ser un evento extraordinario y peligroso. Ratones hay muchos; leones, los hay, pero muy pocos pueden afirmar de haberlos visto. Si alguien ve un león y lo cuenta, puede que no haya quien pueda comprobar esa afirmación, tratándose de un 'arreglo' de la realidad factual que se expone a la comunidad con el objetivo de producir asombro.

Tanto las tallas como los chismes se constituyen como polos diametralmente opuestos sobre una misma línea de acción, siendo dos elementos sustentados en la misma práctica de alterar los eventos de la realidad, pero con resultados completamente diferentes. Corresponden a acciones transformativas, que llevan consigo una intrínseca potencialidad positiva (generando tallas burlescas en un contexto de familiaridad y cercanía) o negativa (generando chismes que eventualmente pueden dañar la reputación de su protagonista). Son la comunidad y el contexto que propicia los hechos los que darán curso a una de estas dos posibilidades, eligiendo de qué forma transformarán al ratón en un león.

¿Qué cosas empujan a una comunidad a modificar los eventos y transmitirlos con irreverentes exageraciones?, ¿de qué modo estos actos pueden ser leídos e interpretados? Podemos partir del supuesto que en esta comunidad las personas hablan y especulan sobre otras, como hemos anteriormente analizado (Bacchiddu 2017). El compartir información sobre los demás, ya sea en un intento jocoso o malicioso, puede formar lazos sociales y reforzar la pertenencia a un grupo, como observa Parkin (1993); asimismo, permite hablar de ciertas conductas sin necesidad de tratarlas de forma explícita, o condenar ciertos actos sin enfrentar a otros. Por ejemplo, Huon Wardle (2001), reflexionando sobre los grafitos presentes en un baño de la Universidad de Belfast, comenta que, siendo la Universidad una institución donde reina un espíritu cosmopolita y un 'teatro de tolerancia', los grafiteros elijen un tipo de escenario que les permite expresarse sin faltar al imperativo de la tolerancia. Desplazando sus confrontaciones imaginarias en un lugar vulgar y marginal, la hegemonía de esta tolerancia es tácitamente reconocida.
En este caso, la reafirmación de ciertas conductas o tópicos que no podrían ser abordados en ningún otro contexto (como las bromas sobre un adulterio, por ejemplo) ocurre de manera general e indirecta, sin nunca tener como objetivo el agredir a alguien específico sino más bien tomando víctimas según lo permitan las circunstancias, reafirmando aún más sus posibilidades abiertas y no necesariamente constreñidas a una única función específica. No obstante, es importante destacar que la explicación de estas prácticas escapa a lo conferido en una hipótesis de corte funcionalista, pues forma parte de algo que es más que el mantenimiento de relaciones entre los individuos. Las personas de Apiao no son confrontacionales y se empeñan en mantener relaciones pacíficas aunque distantes; en este mismo sentido, el tocar temas que pudieran alterar la intimidad o seguridad de otro están prohibidos, referirlos de forma explícita y directa sería un tabú.

En un lugar en donde se hace todo lo que se puede para negociar y adaptarse a las situaciones con el fin de sostener la apariencia de una convivencia pacífica, y mantener la simetría entre todos los habitantes, el poder contar con pequeñas estrategias que permitan desestabilizar este orden, aunque sea temporalmente, es fundamental. Así, tanto bromistas como chismosos se convierten por breves momentos en saboteadores de esta cotidianeidad, haciendo patentes temas que de otra forma no se hablarían, diciéndole a otros cosas que no podrían decirles de forma directa, buscando acceder a información íntima sobre los demás que les está denegada o quebrando la tranquilidad de otros habitantes. De esta manera, ocultamente, se accede al poder inherente que se goza al controlar una situación y al observar la reacción provocada en los interlocutores, lo que representa una forma de dominio que, siendo poco accesible en la comunidad, apetece a algunos. Lo que para unos es un simple ratón, sin ninguna ambigüedad o duda, para otros se transforma creativamente en león, con consecuencias no siempre predecibles, que indudablemente avivan un poco el ritmo cotidiano del vivir isleño.

Agradecimientos: Agradecemos al Centro de Estudios Interculturales e Indígenas (CIIR) que financió parte de la investigación, a los revisores anónimos, a Luis Campos y Francisca Massone por sus comentarios y aportes a versiones anteriores del manuscrito. También agradecemos afectuosamente a los habitantes de la Isla Apiao por compartir sus tallas y sus mentiras, las que son el corazón de este artículo. 


\section{Referencias Citadas}

Apolito, P. 1990. Dice che Hanno Visto la Madonna. Un Caso di Apparizioni in Campania. Il Mulino, Bologna.

Apter, M. 1989. Reversal theory: A new approach to motivation, emotion and personality. Anuario de Psicología 42 (3):19-29.

Bacchiddu, G. 2010. Getting tamed to silent rules: experiencing 'the Other' in Apiao, southern Chile. En Mutuality and Empathy: Self and Other in the Ethnographic Encounter, editado por A.S. Grønseth y D. Lee Davis, pp. 21-34. Sean Kingston Publishing, Wantage.

Bacchiddu, G. 2011. 'Di un topo ne fanno un leone'. Scherzi, battute e bugie ad Apiao, Chiloé (Chile). En Esperienze Etnografiche al Femminile. Complicità, Osservazione e Racconto, editado por F. Lai y F. Sbardella, pp. 67-95. Patron Editore, Bologna.

Bacchiddu, G. 2012a. Mães relutantes, avós maternais e pais esquecidos: o fazer e desfazer das relações de parentesco em Apiao, Chiloé. Revista Tellus 23:35-58.

Bacchiddu, G. 2012b. 'Doing things properly': religious aspects in everyday sociality in Apiao, Chiloé. En Ordinary Lives and Grand Schemes: an Anthropology of Everyday Religion, editado por S. Skielke y L. Debevec, pp. 66-81. Berghahn, New York y Oxford.

Bacchiddu, G. 2017. The danger of knowledge: exercising sameness, bound to differentiation. En The Ethics of Knowledge-Creation. Transactions, Relations and Persons, editado por L. Josephides y A. S. Gronseth, pp. 49-75. Berghahn, New York y Oxford.

Bacchiddu, G. 2019. Ritualising the everyday: the imperative of hospitality in Apiao, Chiloé. Social Analysis 63 (2):122-142.

Barrientos, P. 1997. Historia de Chiloé. Editorial Andujar, Santiago.

Berger, P. 1999. Risa Redentora: La Dimensión Cómica de la Experiencia Humana. Editorial Kairós, Barcelona.

Betz, E. y T. Van Meij1 2016. Humour in the negotiations of social identity in the tongan diaspora. Etnofoor 28 (1):111-125.

Brandrel, A. 2016. The art of conviviality. HAU: Journal of Ethnographic Theory 6 (2):323-343.

Cárdenas, R., D.V. Montiel, C.G. Hall 1991. Los Chonos y los Veliche de Chiloé. Ediciones Olimpho, Santiago.

Clastres, P. 1977. Society Against the State. Urizen Books, New York.

CENSO 2017. Síntesis de Resultados. Instituto Nacional de Estadísticas, Santiago.

Diallo, Y. 2006. Joking relationships in western Burkina Faso. Zeitschrift Für Ethnologie 131 (2):183-196.

Driessen, H. 2015. Humor, anthropology of. En International Encyclopedia of the Social \& Behavioral Sciences, editado por James D. Wright, Vol. 11, pp. 416-419. Elsevier, Amsterdam.

Douglas, M. 1975. Implicit Meanings. Routledge \& Kegan Paul, London.

Gilmore D.1978. Varieties of gossip in a spanish rural community. Ethnology 1:89-99.

Huang, S.W. 2005. Seafood and iodine: an analysis of a medical myth. Allergy and Asthma Proceedings 26 (6):468-469.
Jones, R. 2007. "You eat beans!": kin-based joking relationships, obligations, and identity in urban Mali. Anthropology Honors Projects. Paper 2. http://digitalcommons.macalester.edu/ anth_honor

Kuipers, G. 2016. Follow the joke: humour and ethnography. Etnofoor 28 (2):125-29.

Lévi-Strauss, C. 1969. The Raw and the Cooked. Harper \& Row, New York.

Lagrou, E. 2006. Laughing at power and the power of laughing in Cashinahua narrative and performance. Tipití: Journal of the Society for the Anthropology of Lowland South America 4 (1): 3.

Nachman, S. 1984. Lies my informants told me. Journal of Anthropological Research 40 (4):536-555.

Overing, J. 2000. The efficacy of laughter: the ludic slide of magic within Amazonian society. En The Anthropology of Love and Anger. The Aesthetics of Conviviality in Native Amazonia, editado por J. Overing y A. Passes, pp. 64-81. Routledge, London.

Overing, J. y A. Passes (eds.) 2000. The Anthropology of Love and Anger. The Aesthetics of Conviviality in Native Amazonia. Routledge, London.

Parkin R. 1993. The joking relationship and kinship: charting a theoretical dependency. Journal of Anthropological Society 24 (3): 25163.

Radcliffe-Brown, A. 1940. On joking relationships. Africa 13 (3): 195-210.

Rivera, J.J. (ed.) 2019. Non-humans in Amerindian South America. Ethnographies of Indigenous Cosmologies, Rituals and Songs. Berghahn Books, New York-Oxford.

Rosengren, D. 2010. Seriously laughing: On paradoxes of absurdity among Matsikenga people. Ethnos 75 (1):102- 121.

Said, M. 2016. Humour and lying: male sociality among coastal sinhalese. Etnofoor 28 (1):97-109.

Saldívar, J. 2019. Religión vivida, migración y transnacionalismo. El caso del Nazareno de Caguach en Punta Arenas, Chile, y Río Gallegos, Argentina. Migraciones Internacionales 10: e2184.

Saldívar, J., G. Muñóz, F. Farías y V. Pradines 2018. Mujeres después de la migración, resiliencia, trabajo y vida doméstica en Isla Grande De Chiloé, Chile 1950-1980. Itinerarios. Revista de Estudios Lingüísticos, Literarios, Históricos y Antropológicos 29:238-256.

Salinas, M. 1996. Risa y Cultura en Chile. Documento de Trabajo 1. Departamento de Investigación, Universidad ARCIS, Santiago.

Salinas, M. 1998. En el Chileno el Humor Vive con Uno: El Lenguaje Festivo y el Sentido del Humor en la Cultura Oral Popular de Chile. LOM Ediciones, Santiago.

Salinas, M. 2010. La Risa de Gabriela Mistral. Una Historia Cultural del Humor en Chile e Iberoamérica. LOM Ediciones, Santiago.

Schutz, A. 1945. On multiple realities. Philosophy and phenomenological research. International Phenomenological Society 533-576. 
Ther, F. 2008. Prácticas cotidianas e imaginarios en sociedades litorales. El sector de Cucao, Isla grande de Chiloé. Chungara Revista de Antropología Chilena 40 (1):67-80.

Tobón, M. 2016. Reírse ante la guerra. Las bromas como actuación política entre los muina, Amazonía colombiana. Revista Mexicana de Sociología 78 (2):179-202.

Toren, C. 2005. Laughter and truth in Fiji: What we may learn from a joke. Oceania 75:268-283.

Para otra reflexión sobre estos mismos temas, si bien con premisas y interpretaciones diferentes, y el análisisde un número mayor de casos, véase Bacchiddu 2011.

2 La investigación relacionada con los datos analizados en este artículo es parte de un estudio más amplio,de largo plazo, que abarca diferentes temáticas. La metodología combinó observación participante con recopilaciones de narrativas relacionadas con eventos específicos, así como historias de vida. Durante la estadía en la isla se participó activamente a los eventos comunitarios, con particular énfasis en aquellos celebrados como novenas de santo o de muerto, carneos y reitimientos de chanchos, maja de manzana, siembras, cosechas, botas de lancha, tiraduras de casa, entre otros. La prolongada estadía y la repetidas visitas han permitido desarrollar una familiaridad reciproca con lugareños de diferentes generaciones.

3 Este sector corresponde a dos grupos de islas formados por Alao, Apiao y Chaulinec y por Cahuach (o Caguach), Lin-Lin, Llingua, Meulín, Quenac y Teuquelín.

4 Cada vez que alguien pide algo, su actitud involucra una performance ritualizada de humildad y modestia. Pedir es, en cierto sentido, invadir la privacidad de alguien, creando un desbalance de poder que debe corregirse. La modestia
Urbina, B.R. 1983. La Periferia Meridional Indiana. Chiloé en el Siglo XVIII. Ediciones Universitarias de Valparaíso, Valparaíso.

Veira, J.L. 2018. As teorías do humor e o cambio cultural. Anuario Psicoloxía e Saúde: Revista Oficial da Sección de Psicoloxía e Saúde do COPG 11:9-20.

Weber, A.S. 1903. Chiloé. Su Estado Actual, Su Colonización, Su Porvenir. Imprenta Mejía, Santiago.

Zires, M. 2005. Del Rumor al Tejido Cultural y Saber Político. UAM-Unidad Xochimilco, Xochimilco.

\section{Notas}

funciona como un dispositivo estilístico para anticipar y preparar al interlocutor para lo que viene. Para más detalles véase Bacchiddu 2010, 2019.

5 Se debe considerar que estos actos forman parte de la memoria histórica de Chiloé en general, pudiendo trasladarse hacia diferentes lugares de la Patagonia Chilena y Argentina, producto de la migración de sus habitantes y la construcción de asentamientos en otros territorios. Actividades como las celebraciones religiosas locales a los Santos patronos o actividades colectivas como las mingas son una parte activa en el mantenimiento del sentido comunitario y la construcción de la comunidad (para mayores detalles, véase Saldívar 2019).

6 Las relaciones sociales en Apiao vienen mediadas a través de la oferta de alimentos y bebidas. El hecho de que la joven francesa siguiera una dieta diferente le impedía compartir algunos alimentos, acentuando su peculiaridad. En lo que respecta a este trabajo de campo, la inserción en el grupo pasó a través de varias fases, siempre marcadas por distintos niveles de participación en distintas comidas, lo que destaca la importancia de ciertas prácticas ligadas a la convivencia en la socialización con el otro en el contexto chilote.

7 Los Chilotes denominan comúnmente 'león' al puma (Puma concolor puma). 
